\title{
Oxalate induces breast cancer
}

\author{
Andrés M. Castellaro ${ }^{1}$, Alfredo Tonda ${ }^{2}$, Hugo H. Cejas ${ }^{3}$, Héctor Ferreyra² ${ }^{2}$ Beatriz L. Caputto ${ }^{1}$, Oscar A. Pucci ${ }^{*}$ \\ and German A. Gil ${ }^{1 *}$
}

\begin{abstract}
Background: Microcalcifications can be the early and only presenting sign of breast cancer. One shared characteristic of breast cancer is the appearance of mammographic mammary microcalcifications that can routinely be used to detect breast cancer in its initial stages, which is of key importance due to the possibility that early detection allows the application of more conservative therapies for a better patient outcome. The mechanism by which mammary microcalcifications are formed is still largely unknown but breast cancers presenting microcalcifications are more often associated with a poorer prognosis.

Methods: We combined Capillary Electrochromatography, histology, and gene expression (qRT-PCR) to analyze patient-matched normal breast tissue vs. breast tumor. Potential carcinogenicity of oxalate was tested by its inoculation into mice. All data were subjected to statistical analysis.
\end{abstract}

Results: To study the biological significance of oxalates within the breast tumor microenvironment, we measured oxalate concentration in both human breast tumor tissues and adjoining non-pathological breast tissues. We found that all tested breast tumor tissues contain a higher concentration of oxalates than their counterpart nonpathological breast tissue. Moreover, it was established that oxalate induces proliferation of breast cells and stimulates the expression of a pro-tumorigenic gene $c$-fos. Furthermore, oxalate generates highly malignant and undifferentiated tumors when it was injected into the mammary fatpad in female mice, but not when injected into their back, indicating that oxalate does not induce cancer formation in all types of tissues. Moreover, neither human kidney-epithelial cells nor mouse fibroblast cells proliferate when are treated with oxalate.

Conclusions: We found that the chronic exposure of breast epithelial cells to oxalate promotes the transformation of breast cells from normal to tumor cells, inducing the expression of a proto-oncogen as c-fos and proliferation in breast cancer cells. Furthermore, oxalate has a carcinogenic effect when injected into the mammary fatpad in mice, generating highly malignant and undifferentiated tumors with the characteristics of fibrosarcomas of the breast. As oxalates seem to promote these differences, it is expected that a significant reduction in the incidence of breast cancer tumors could be reached if it were possible to control oxalate production or its carcinogenic activity.

Keywords: Microcalcifications, Oxalate, Calcium Oxalate, Breast Cancer Induction

\section{Background}

Cancer is one of the major public health problems of the world. Among the different types of cancer, breast cancer is one of the most frequently diagnosed one and the leading cause of cancer death in females around the world. [1, 2]. One shared characteristic of breast cancer is the appearance of mammographic

\footnotetext{
* Correspondence: oscar_pucci@hotmail.com; ggil@fcq.unc.edu.ar

2Primera Cátedra de Ginecología, Hospital Nacional de Clínicas, Universidad

Nacional de Córdoba, Córdoba, Argentina

'Departamento de Química Biológica, Facultad de Ciencias Químicas,

Universidad Nacional de Córdoba- CIQUIBIC, CONICET, Córdoba, Argentina

Full list of author information is available at the end of the article
}

mammary microcalcifications. These microcalcifications are routinely used to detect breast cancer in its early stages, which is of key importance because early detection allows the application of more conservative therapies and results in a better patient outcome. Up to $50 \%$ of all non-palpable breast cancers are detected solely through microcalcifications observed in mammogram scans whereas up to $93 \%$ of cases of ductal carcinoma in situ (DCIS) present microcalcifications [3]. Studies have shown that breast cancers presenting with microcalcifications are more often associated with lymph node 
invasion [4] and HER-2 positivity [5, 6], which results in a poorer prognosis.

Mammary microcalcifications can be classified at the molecular level in two different types well distinguished by their physical and chemical properties. -Type I calcifications that are composed of calcium oxalate $(\mathrm{CaOx})$, are amber in color, partially transparent and form pyramidal structures with relatively planar surfaces. -Type II calcifications that are composed of calcium phosphate, mainly hydroxyapatite (CaP), are grey-white, opaque and form ovoid or fusiform shapes with irregular surfaces [7].

$\mathrm{CaOx}$ crystals have been associated both with invasive carcinomas as well with in situ lesions [8]. However, $\mathrm{CaOx}$ crystals are mainly related to diverse benign cystic breast lesions [9-11]. Thus, $\mathrm{CaOx}$ crystals in breast biopsies are often clinically significant and although it is important to detect their presence, $\mathrm{CaOx}$ Crystals usually are not clearly visible on routine histologic sections. Therefore, it is recommended the examination of all breast biopsies under polarized light to clearly see $\mathrm{CaOx}$ crystals. The mechanism by which mammary microcalcifications are formed is still largely unknown. No clear demonstration has shown if an active cellular process produces microcalcifications or if these are the result of cellular degeneration. Some results support the hypothesis that $\mathrm{CaOx}$ would be a secretion product whereas $\mathrm{CaP}$ could be formed due to an active process similar to the one involved in the physiological mineralization of bone rather than a passive, end stage process associated with cellular degeneration. Furthermore, other groups find that epithelial cells acquire mesenchymal characteristics and become capable of producing breast $\mathrm{CaOx}$ microcalcifications [10-12].

Oxalate has also been found as an inert metabolic end product because mammalian cells cannot metabolize it. Oxalate is an organic dicarboxylate that may be present as free oxalic acid, as soluble salts such as sodium or potassium oxalates, or as insoluble salts such as calcium oxalate crystals [13, 14]. Additionally, oxalate is produced by many kinds of cells, including liver cells, kidney, epithelial cells and apocrine cells, among others [8, 12, 15-18]. Oxalate deposits are associated with renal cysts in acquired renal cystic disease, hyperplastic thyroid glands, and benign neoplasms of the breast [19]. In breast, apocrine cells originate from the terminal duct-lobular unit and not from axillary apocrine sweat glands $[15,20]$. Apical secretory snouts are usually found in cells of the apocrine metaplasia, and intra-cytoplasmic vacuoles are present. Intraluminal calcium oxalate crystals have been occasionally seen in association with apocrine metaplasia, especially in dilated ducts [20].

It is supposed that the accumulation of oxalate is toxic to living tissue since it induces some pathological circumstances, as mentioned above. Indeed, exposure of renal epithelial cells to oxalate triggers diverse events that include a plethora of cellular changes on the p38 MAPK pathway activity, induction of immediate early gene expression like c-fos gene and re-initiation of DNA synthesis, among others $[21,22]$. Furthermore, oxalate stimulates IL-6 production in human renal proximal tubular epithelial cells [23-25]. By Affimetrix gene expression it was found 750 up-regulated and 2276 down-regulated genes in renal cells exposed to oxalate.

Despite the importance of mammary microcalcifications for the early detection of breast cancer and their potential prognostic and biological relevance, little research has been carried out to investigate its function and even more, to the best of our knowledge, no one has considered free oxalate as an important inductor of breast pathologies. Scarce research has been carried out directed to specifically investigate the impact that the presence of oxalates has on the breast tumor microenvironment. Neither the interactions between oxalate breast-epithelial cells are well understood nor have been elucidated the signal transduction pathways involved in it. Herein, we have obtained evidence supporting the hypothesis that the chronic exposure of breast epithelial cells to oxalates induces alterations in normal breast epithelial cells promoting the transformation of breast cells from normal to tumor cells.

\section{Methods}

\section{Oxalate determination}

Using an Ultra-turrax homogenizer, either human or murine breast tissues were processed in hydrochloric acid $2.75 \mathrm{M}$. Always a ratio of 1:5 was maintained between the milligrams of tissue and micro-liters of hydrochloric acid used, approximately $200 \mathrm{mg}$ of breast tissue (tumor or not) was homogenized in $1000 \mu \mathrm{L}$ of hydrochloric acid. Then it was centrifuged for $15 \mathrm{~min}$ at $15,000 \mathrm{xg}$ and the supernatant fraction (SF) was stored at $-20{ }^{\circ} \mathrm{C}$. Total Oxalate concentrations in the SF's were quantified using capillary electrochromatography (CEC) (Beckman Coulter).

\section{Tissue homogenates for protein analysis}

Using an Ultra-turrax homogenizer, either human or murine breast tissues were processed in RIPA buffer $(\mathrm{NaCl}$ $150 \mathrm{mM}$, Tris- $\mathrm{HCl} 50 \mathrm{mM}$, EDTA 0,5 mM, Tritón 1 \% y SDS $0,1 \%$ ) plus complete protease inhibitor cocktail [7]. Always a ratio of 1:5 was maintained between the milligrams of tissue and micro-liters of buffer used, approximately $200 \mathrm{mg}$ of breast tissue (tumor or not) was homogenized in $500 \mu \mathrm{L}$ of buffer. This process was made on ice $\left(4^{\circ} \mathrm{C}\right)$ and then centrifuged for $15 \mathrm{~min}$ at $15,000 \mathrm{xg}$ using a cooling centrifuge $\left(4{ }^{\circ} \mathrm{C}\right)$ to separate the microsomal [26] and supernatant (SF) fractions. SF was stored at $-20{ }^{\circ} \mathrm{C}$ to future protein analysis by SDS page and Western Blot. 


\section{Cell cultures and extracts}

MCF-7, MDA-MB231, MCF-10A, NIH-3 T3 and HEK293 cells (ATCC-Bethesda, MD, USA) were grown under standard culture conditions in Dulbecco's modified Eagle medium (Gibco, BRL, Invitrogen, Carlsbad, CA, USA) supplemented with $10 \%$ fetal bovine serum (FBS). MCF$10 \mathrm{~A}$ cells were grown under standard culture conditions in DMEM/F12 (Gibco, BRL, Invitrogen, Carlsbad, CA, USA) supplemented with $10 \%$ fetal bovine serum (FBS) and additionally have the following supplements: EGF $20 \mathrm{ng} / \mathrm{ml}$, Hydrocortizone 0,5 mg/ml, Cholera Toxin $100 \mathrm{ng} / \mathrm{ml}$, Insulin $10 \mu \mathrm{g} / \mathrm{ml}$. After desired confluence, growth was continued for $48 \mathrm{~h}$ (MCF-7, MCF-10A, NIH-3 T3 and HEK-293 cells) or $72 \mathrm{~h}$ (MDA-MB231 cells) with serumfree media (-FBS) to achieve quiescence. Cells reentered growth by addition of $10 \%$ FBS or cultures continued with serum-free media (-FBS), as indicated in the experiments. Obtaining of total homogenate $(\mathrm{TH})$ from attaches cell: Cell growth medium was removed from $35 \mathrm{~mm}$ well and then cells were rinsed with PBS. After that, cells were lysed with $90 \mu \mathrm{L}$ of RIPA buffer $(\mathrm{NaCl} 150 \mathrm{mM}$, Tris- $\mathrm{HCl}$ $50 \mathrm{mM}$, EDTA 0,5 mM, Tritón $1 \%$ y SDS 0,1 \%) plus complete protease inhibitor cocktail [7] using a scrapper and then centrifuged for $15 \mathrm{~min}$ at $15,000 \mathrm{xg}$ using a cooling centrifuge $\left(4{ }^{\circ} \mathrm{C}\right)$ to separate the microsomal [26] and supernatant (SF) fractions. SF was stored at $-20{ }^{\circ} \mathrm{C}$ to future protein analysis by SDS page and Western Blot.

\section{Protein quantification}

Total protein concentration in the SF from TH of cells or tissues (for more details see above) was performed using Bradford standard colorimetric method (Bio-Rad protein assay).

\section{SDS - Polyacrylamide gel electrophoresis and western blot assays}

$60 \mu \mathrm{g}$ of total protein from $\mathrm{TH}$ of cells or tissues (for more details see above) was subjected to SDS-gel electrophoresis according to Laemmli. The gel concentration was $12 \%$ and the acrylamide - bisacrylamide ratio was 30 and $0.8 \% \mathrm{p} / \mathrm{v}$ respectively. The separated proteins were electrotransferred to PVDF membrane (pore size $0,2 \mu \mathrm{m}$, Westran S, Sigma-Aldrich) at $300 \mathrm{~mA}$ for $1 \mathrm{~h}$ according to Anthony K. Tan. For immunoblotting, nonspecific binding sites were blocked with PBS containing $5 \%$ non-fat milk and Tween $200.05 \% \mathrm{p} / \mathrm{v}$, for $1 \mathrm{~h}$ at room temperature. Blocked membranes were incubated overnight at $4{ }^{\circ} \mathrm{C}$ in PBS-Tween $200.05 \%$ p/v with: rabbit anti-c-Fos monoclonal antibody (Sigma-Aldrich, dilution 1/1000), rabbit anti c-Jun (Sigma-Aldrich, dilution 1/1000), mouse anti $\alpha$-tubulin DM1A mAb (SigmaAldrich, dilution 1/5000). Washed membranes were incubated $1 \mathrm{~h}$ at room temperature with IRDye 680LT antirabbit or IRDye $800 \mathrm{CW}$ anti-mouse antibody $(1 / 25,000$, LI-
COR Bioscience, Lincoln, NE, USA), washed and immunodetection performed using ODYSSEY Infrared Imaging System (LI-COR Bioscience).

\section{Real time-RT-PCR}

Total RNA was extracted from breast tissue and cell lines using Trizol Reagent (Invitrogen) and an RNeasy Mini Kit (Qiagen) respectively. One microgram of total RNA was transcribed into cDNA using the SuperScript ${ }^{\text {tu }}$ III First-Strand Synthesis System (Invitrogen). The qRTPCR primers (Taqman) were purchase from Applied Biosistem. Specific transcripts were quantified by real time qRT-PCR (ABI 7500 Sequence Detection System, Applied Biosystems) using the Sequence Detection Software v1.4. The primers used to measure human and mouse $c$-fos mRNA expression were Hs04194186_s1 and Mm00487425_m1 respectively. Gene expression of human $c$-fos was normalized to GAPDH using the primer Hs99999905_m1 (MCF-7 cells) or to RPLPO using the primer Hs99999902_m1 (HEK cells). Gene expression of mouse $c$-fos was normalized to Tbp using the primer Mm00446973_m1. The relative gene expression was calculated using the $2^{-\Delta \Delta \mathrm{Ct}}$ method. Each sample was analyzed in quadrupled.

\section{Cell proliferation assay}

Cell proliferation was assessed using the CyQUANT ${ }^{\circ}$ cell proliferation assay kit (Molecular Probes Inc., OR, USA) or counting cells with a Neubauer Chamber. In the first method, the trademarked CyQUANT ${ }^{\circ}$ dye binds to DNA, and the fluorescence emitted by the dye is linearly proportional to the number of cells in the well. Cells were plated in 96-well black fluorescence plates, at a density of 4000 cells/well. Experiments were carried out at least three times by quadruplicated. In the counting cells method, cells were plated in 6-well plates at a density of 30,000 cells/well and also they were carried out at least three times by quadruplicated. Cells were cultured by three days at different conditions and after that, cells were trypsinized and counted by triplicate using the Neubauer Chamber.

\section{Ethics statement}

Freshly excised human breast tumor and matched benign specimens were obtained from female patients after they were informed about all process and signed the consent accepting to participate in this study (Informed Consent). The Research Ethics Board of the Hospital Nacional de Clinicas, Universidad Nacional de Cordoba, Argentina, approved all the procedures used for this study (with the Helsinki Declaration of 1975, as revised in 1983). Samples were processed anonymously. Patient ages ranged from 38 to 82 years old. 


\section{Animals}

Female BALB/c or BALB/c nude mice (Charles River) were injected into the left inguinal mammary fatpad with $50 \mu \mathrm{L}$ of oxalic acid $810 \mu \mathrm{M}$ in a carrier solution containing $\mathrm{CaCl}_{2} 1.8 \mathrm{mM}$ (experimental group), with carrier solution or with carrier solution plus acetic acid $810 \mu \mathrm{M}$. Animals received 9 injections in a period of 29 days (one injection every three or four days) of $50 \mu \mathrm{L}$ each one. To avoid the formation of oxalate microcrystals mice were injected into the left inguinal mammary fat pad with potassium oxalate $810 \mu \mathrm{M}$ in a carrier solution. Also the mice were injected in the back with the same solutions potassium oxalate $810 \mu \mathrm{M}$, acetic acid $810 \mu \mathrm{M}$ or carrier solution. Animals received 7 injections in a period of 18 days (one injection every two or three days) of $50 \mu \mathrm{L}$ each one. When tumors were over $1000 \mathrm{~mm}^{3}$, mice were euthanized for tissue collection or when the animals were in no healthy condition. All animal breast tissues were stained for H\&E. Two independent pathologists made histopathological analyses. All mice were grown under standard conditions. The Ethics Committee of the Department of Chemical Biology, UNC, Argentina, approved all the procedures used for this study.

\section{Macrodissection}

To perform macrodissection, 3-5 serial $10-\mu \mathrm{m}$ sections of tumor were adhered to uncharged slides using nucleasefree water. One additional $5-\mu \mathrm{m}$ adjacent section was stained for H\&E. An expert breast histopathologist outlined the tumor hotspot region. Each slide from the block was then overlaid on the H\&E-stained slide and oriented according to the features of the section. The area surrounding the tumor-dense target region was scraped away using a sterile razor blade; the remaining tumor region was scraped into a 1.7-ml tube using a fresh blade. This process was repeated for all of the sections for each macro-dissected sample.

\section{Immunohistochemistry}

Breast Tumor Tissue specimens were de-waxed and rehydrated as described [27] and incubated overnight at $4{ }^{\circ} \mathrm{C}$ with rabbit anti-c-Fos monoclonal primary antibody (Sigma-Aldrich, dilution 1/300) diluted in blocking buffer. Sections were rinsed 3 times with PBS $10 \mathrm{mM}$ plus $0.1 \%$ Tween 20 (PBS-tween) and then incubated with anti-rabbit Alexa 488 secondary antibody (dilution 1/ 500, Molecular Probes, Eugene, OR, USA) for $2 \mathrm{~h}$ at RT. Sections were rinsed three times with PBS-tween and nuclei were stained by incubation with 4',6-diamidino-2-phenylindole (DAPI) $20 \mathrm{~min}$ and rinsed again with Milli-Q water. Slides mounted with FluorSave (Calbiochem, San Diego, CA, USA) were visualized under an Olympus FV1000 or Pascal 5 laser scanning confocal microscope using Olympus (Centre Valley,
PA, USA) or Carl Zeiss (St Louis, MO, USA) software for image analysis.

\section{Statistical analyses}

Each statistical analysis applied to the results has been clarified in the corresponding legends to the figure. Survival curves of Fig. 5 were statistically analyzed by LogRank (Mantel-Cox) test whereas statistical significance analysis by Two-way ANOVA with Holm-Sidak's multiple comparation test $(\alpha=0.05)$ was performed in experiments graphed in Fig. 2a and Additional file 1: Figure S1. One- way ANOVA with Holm-Sidak's test was used in Figs. 2b, 4c and $d$ [28]. Figures 1 and 6 were statistically analyzed by Student's two-tailed $t$-test. All graphs were performed using GraphPad Prism version 6.0e for Mac OS X (GraphPad Software, La Jolla California USA).

\section{Results}

\section{Oxalate levels are increased in human breast tumor} tissues

In order to study the biological implications of Oxalates within breast tumors, first oxalate concentration was determined using Capillary Electrochromatography (CEC) in both human breast tumor tissues and tumor-adjacent non-cancerous breast tissues. Eleven breast tumor samples (Tumor samples) and the same numbers of noncancerous breast tissues (Control samples) were analyzed. Most of the paired-samples were obtained from a same patient and each patient was randomly selected. Surprisingly, we found that all breast tumor tissues examined have a higher concentration of total oxalate than their

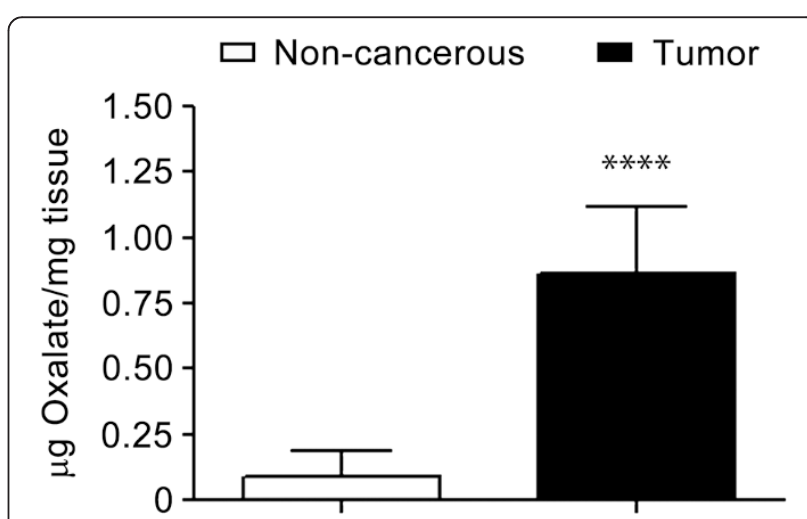

Fig. 1 Human breast tumor tissues have higher concentration of total Oxalate than non-cancerous breast tissues. 13 samples of human breast tumor tissues (Tumor samples) and 12 samples of tumor-adjacent non-cancerous breast tissues (Control samples) were homogenized in $2.75 \mathrm{M}$ hydrochloride acid. The supernatant fractions were analyzed by Capillary Electrochromatography to establish the total concentration of oxalate present in each sample. Results of oxalate concentrations are expressed as $\mu \mathrm{g}$ oxalate/mg of tissue $(n=13$ and $n=12$ were analyzed for tumor and non-tumor samples, respectively); statistical significance was calculated using Student's two tailed $t$-test. ****P value $<0.0001$ 
counterpart non-cancerous breast tissue. The average concentration of total oxalate present in the tumor samples was almost 10 times higher than that of the control samples. A significant difference between tumors vs. control was found after analyzing results for statistical significance using Student's two tailed $t$ test (Fig. 1).

\section{Oxalate induces proliferation of breast cells}

Due to the high concentration of oxalate found in breast tumor tissues relative to breast non-tumor tissues, we hypothesized that oxalate could produce a particular effect at the cellular level that would favor the genesis and growth of breast tumors. Therefore, breast cancer cell lines were treated in culture with different concentrations of oxalate and then proliferation was measured. Cell proliferation assays were performed using two different techniques, that is, measuring total DNA (Fig. 2a) and counting cells (Additional file 1: Figure S1). The experiments were performed three times in quadruplicate.

These proliferation experiments showed that oxalate at concentrations of 20 and $50 \mu \mathrm{M}$ induces significantly higher rates of proliferation of MCF-7, MDA-MB231 cell lines after three days of treatment as determined by Two-way ANOVA with Holm-Sidak's multiple comparison test $(\alpha=0.05)$ (Fig. 2a). Furthermore, MCF-7 cells treated for three weeks with lower concentrations of oxalate $(1 \mu \mathrm{M}, 5 \mu \mathrm{M}$ and $15 \mu \mathrm{M})$ also showed a significant increase in their proliferation rates as determined by One- way ANOVA with Holm-Sidak's test (Fig. 2b). It is important to note that in all cases the effect of oxalate was evaluated using the same culture medium as used for the corresponding control. To exclude any possible involvement of the $\mathrm{pH}$ in this phenomenon, for each case acetic acid was used as an additional control, at the same concentration as the oxalate. As expected, none of the acetic acid concentrations had any significant effect on cell proliferation as shown in Fig. 2a and b. Similar controls were performed with fumaric acid and essentially the same results were obtained (not shown). Interestingly, oxalate has no effect on other cell types, such as HEK-293 cells (Fig. 2a) or NIH-3 T3 cells (Additional file 1: Figure S1), indicating that this phenomenon is restricted mainly to breast cells. However, normal breast cell lines such as MCF-10A cells were treated for three days with oxalate (at $20 \mu \mathrm{M}$ or $50 \mu \mathrm{M}$ ) but proliferation induction was not clearly observed (results not shown). Consequently, MCF-10A cells were treated with oxalate for a longer period of time (seven days) with the same concentrations that above (Fig. 2a). Under these latter experimental conditions of prolonged treatment with oxalate, a slight induction of proliferation was observed in normal breast cells line but of a smaller magnitude than the induction promoted by treatment of these cells with FBS plus EGF. Furthermore, in no case was this induction of a similar magnitude to that obtained after treatment of the breast cancer cells lines with FBS or with oxalate (Fig. 2a). This was the first indication that oxalate has a proliferative effect on breast cells.

\section{Oxalate induces overexpression of c-Fos in MCF-7 cells}

fos and jun oncogenes are members of the family of Immediate Early Genes (IEGs) that are rapidly and transiently expressed in different cell types in response to a myriad of stimuli, such as growth factors, neurotransmitters, etc. [19, 27, 29-32]. Although c-Fos was described as an AP-1 transcription factor more than 25 years ago, the complex consequences of its induction on cell's physiology have still not been fully elucidated. It has been proposed that, upon mitogenic stimuli, c-Fos triggers and controls cell growth, differentiation and apoptosis by regulating key genes. Furthermore, c-Fos was also described as a cytoplasmic activator of the biosynthesis of lipids both in normal and pathological cellular processes that demand high rates of membrane biogenesis [33]. c-Fos and Its family members are probably the most frequently expressed IEGs in different forms of human cancer: its overexpression has been reported in proliferative disorders such as breast, lung, colon, brain and thyroid cancers $[27,30,34]$. We analyzed c-Fos expression by Western Blot in both human breast tumor tissues and non-cancerous breast tissues adjacent to tumors. Both types of tissues were taken in pairs from patients. As expected, we also observed high rates of c-Fos expression in breast tumor tissues, whereas noncancerous tissues showed little or non-detectable levels of c-Fos expression confirming the results of Motrich et al. [34] (Fig. 3). Consequently, we evaluated the possible effect of oxalate on breast cancer cell lines in terms on inducing c-Fos expression. This evaluation was done by exposing MCF-7 cells to different concentrations of oxalate for $1.5 \mathrm{~h}$ and then c-Fos expression was measured by Western Blot (Fig. 4a). c-Fos over-expression is induced by oxalate in a concentration range between 20 and $50 \mu \mathrm{M}$ in MCF-7 cells. This result reveals for the first time that oxalate can activate the pathway of an IEG such as $c$-fos, exhibiting a genomic effect, in breast cancer cells. Conversely, HEK-293 (Fig. 4b) and NIH-3 T3 (Additional file 2: Figure S2) cells were treated with oxalate in parallel to MCF-7 cells, but neither non-breast cell lines over-expressed c-Fos showing that this effect is limited to breast cells. This result is in accordance with the previous one, in which it is showed that the effect of oxalate on proliferation is observed mainly in breast cells. We also tested the induction of other IEG as c-Jun by oxalate in MCF-7 cells in the same condition that above. c-Jun expression was not induced by oxalate as its shown in the Western Blot in Additional file 3: Figure S3. 


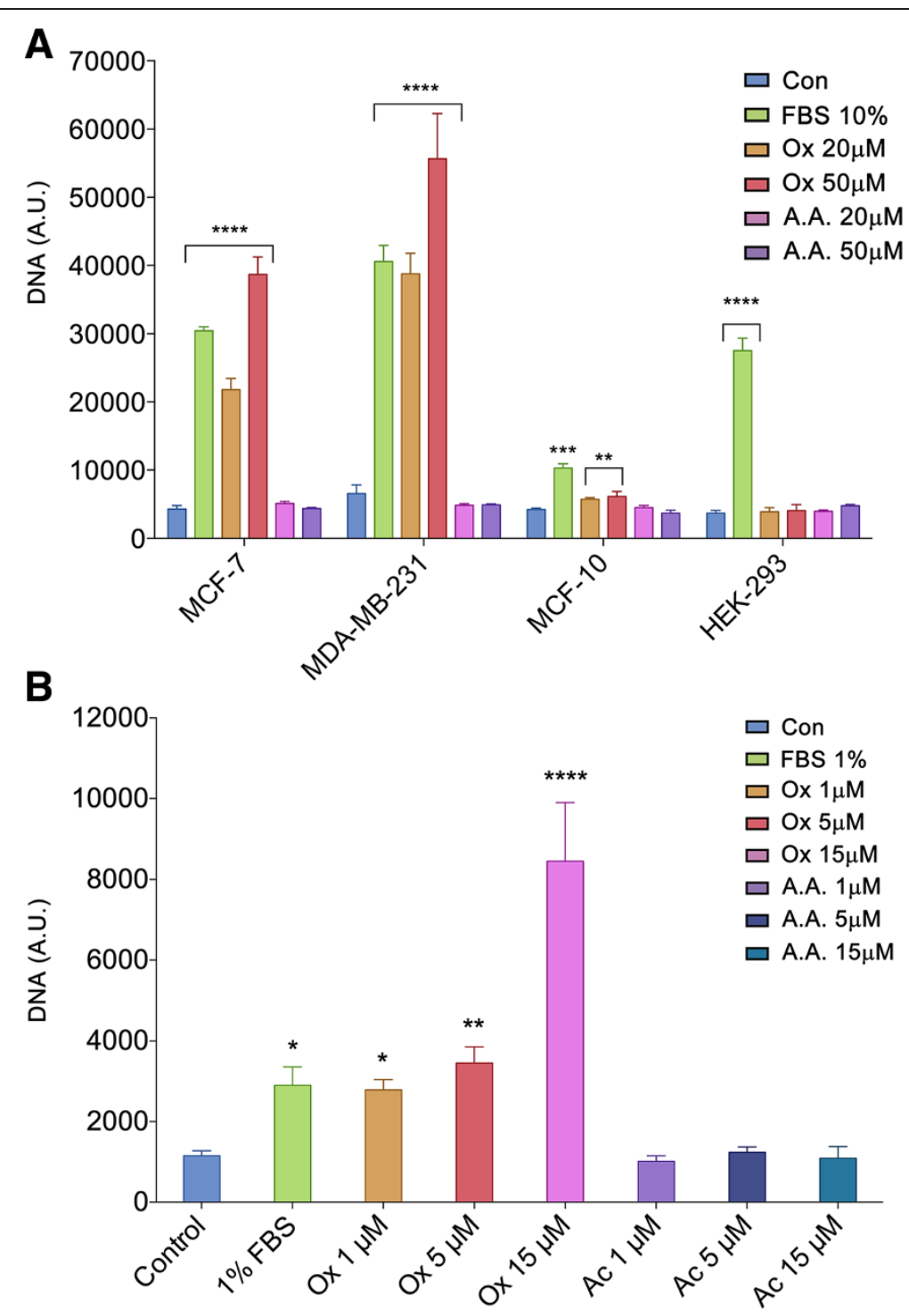

Fig. 2 Oxalate induces breast cancer cell proliferation. Proliferation was performed using a colorimetric assay and following the manufacturing instructions (CyQUANT, Life Technologies) in cells (a) after 3 days of treatment of MCF-7, MDA-MB231, HEK-293 or 7 days of treatment of MCF$10 \mathrm{~A}$ cells (a) as indicated with oxalate or with acetic acid, or (b) after 3 weeks of treatment in of MCF-7 cells. Cells were cultured in DMEM medium plus an additional specific reagent or not, according to each condition, as indicated. Con: Control, no additional reagent was added; FBS: fetal bovine serum, Ox: oxalic acid or A.A.: acetic acid were added to the culture medium. Results are expressed as DNA content (arbitrary units) found after seeding $4 \times 10^{3}$ cells/well.. Bars represent the standard error of the mean of four independent experiments performed in triplicate. A.U.: arbitrary units. Statistical significance determined by Two-way ANOVA with Holm-Sidak's multiple comparison test $(a=0.05)$ were performed in experiments graphed in Fig. 2a. One- way ANOVA with Holm-Sidak's test was performed in Fig. 2b. ****:P value $<0.001 ;{ }^{* *} P$ value $<0.01 ;{ }^{*} P$ value $<0.05$

To further confirm that oxalate can activate the pathway of $c$-fos in MCF-7 cells but not in HEK-293 cells, we measured the transcription level of this gene by q-RTPCR. For this, both cell lines were treated as described previously for $1.5 \mathrm{~h}$ with oxalate and then $c$-fos mRNA measured. As expected, over-expression of $c$-fos mRNA was found in MCF-7 cells treated with oxalate (Fig. 4c) but not in HEK-293 cells (Fig. 4d).

\section{Oxalate induces breast tumors in mice}

In order to well define if oxalate triggers breast cancer in vivo, we treated mice with oxalate, mimicking in vitro proliferation experimental conditions described before. Consequently, eigth mice were injected into the left inguinal mammary fat pad (mammary fat pad) with $50 \mu \mathrm{L}$ of a solution containing microcrystals of calcium oxalate at a concentration of $810 \mu \mathrm{M}$ (experimental group). To 


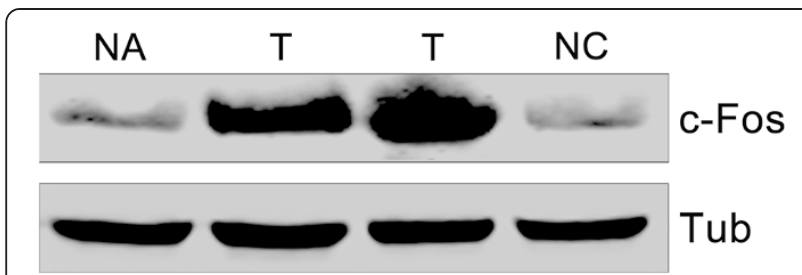

Fig. 3 c-Fos is over-expressed in human breast tumor tissues. Western Blot of Breast tumor tissue (T) and paired tumor-adjacent non-cancerous tissue (NA) from a patient, together with a non-paired non-cancerous breast tissue (NC) (as an additional control) were fractionated in $12 \%$ SDS-PAGE gel and immunoblotted using anti-c-Fos and anti a-Tubulin antibodies. a-Tubulin was used as loading control. The blot shown is representative of five independent experiments performed that gave similar results

obtain the microcrystals of calcium oxalate, $1.8 \mathrm{mM}$ $\mathrm{CaCl}_{2}$ was added to the solution of oxalic acid previous to being injected into the mice. Two additional groups (six mice each) were injected either with $50 \mu \mathrm{L}$ of carrier solution plus acetic acid $810 \mu \mathrm{M}$ or $50 \mu \mathrm{L}$ of carrier solution alone, also into the mammary fat pad region (control groups). The mice that received injections containing acetic acid were an extra control to exclude any possible effect of $\mathrm{pH}$ or injury due to the frequency of injections used. Altogether, the mice received nine doses (one injection every 3 or 4 days) in a period of 29 days (1 dose every 3.2 days on average). After the last dose was applied, mice were examined and no tumor formation was observed. However on day 64 (35 days after the last dose was injected) a palpable tumor appeared at the mammary fat pad region in a mouse of the experimental group. On day 73, most mice of this experimental group had at least one tumor ( 6 of 8 mice), at the mammary fat pad region. Finally, on day 75 , all mice injected with oxalate had developed tumors at the mammary fat pad area and some of them presented palpable metastatic tumors in the chest region. The survival curves of Fig. 5a clearly show the statistically significant differences between survival curves as analyzed by LogRank (Mantel-Cox) test. Tumor volume (v) of each mice was measured and calculated in accordance with the formula of Attia and Weiss [35], $\mathrm{v}=0.4 \times\left(\mathrm{a} \mathrm{x} \mathrm{b}^{2}\right)$, in which (a) is the largest and (b) is the smallest diameter of each tumor. All mice injected at the mammary fat pad area with oxalate had developed tumors but not those of the two other groups (Fig. 6). The volume of tumors originated after oxalate treatment vs. the volume of non-pathological samples of the controls (volume $=\mathrm{mm}^{3}$ ) was highly significant as analyzed using Student's two tailed $t$-test (Fig. 6). Subsequently, oxalatetreated mice were sacrificed at different times once they were not healthy according to ethical conditions (see Materials and Methods) and a histological examination of the organs was performed. All organs such as kidneys, lungs, liver, spleen and bowels were found pathologically normal. Control mice were subjected to a 6-month follow-up, time at which they were examined in vivo and then sacrificed to perform a histological examination of all organs. No tumor formation was found in any of the control mice after performing both types of examinations (Figs. 5a and 6).

In the above-mentioned experiment in vivo, the experimental group received injections containing oxalate $810 \mu \mathrm{M}$. However, under these experimental conditions, most of the oxalate is in the microcrystal state as calcium oxalate and the concentration of free oxalate is
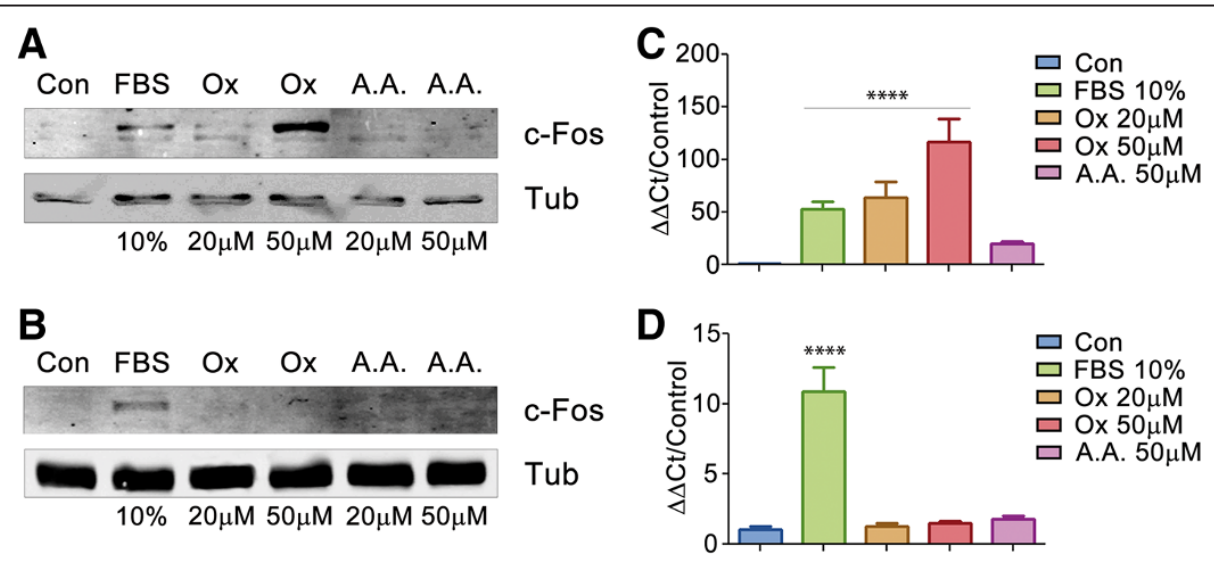

Fig. 4 Oxalate induces expression of c-Fos in MCF-7 cells but not in HEK-293 cells. Cells were plated in six wells and grown to $80 \%$ of confluence. Then cells were starved to achieve quiescence (see M \& M). After that, each experimental condition was achieved by the stimulation with the specified reagent during 1.5 h. MCF-7 (a) or HEK-293 (b) cells were lysed, then the supernatant fractions were separated in $12 \%$ SDS-PAGE gel and immunoblotted using anti-c-Fos antibody. a-Tubulin was used as loading control. c-fos expression was measured in MCF-7 (c) or HEK-293 (d) cells by qRT-PCR and normalized against housekeeping genes (GAPDH for MCF-7 cells and RPLPO for HEK-293 cells) using the Sequence Detection Software v1.4. Shown are the mean values of 3 independent determinations performed in quadruplicate. Con: Control, No reagent addition FBS: fetal bovine serum. Ox: oxalic acid. A.A.: acetic acid. Statistical significance determined by One- way ANOVA with Holm-Sidak's test was performed in experiments shown in Fig. $4 c$ and $d^{* * * *} P$ value $<0.0001$ 

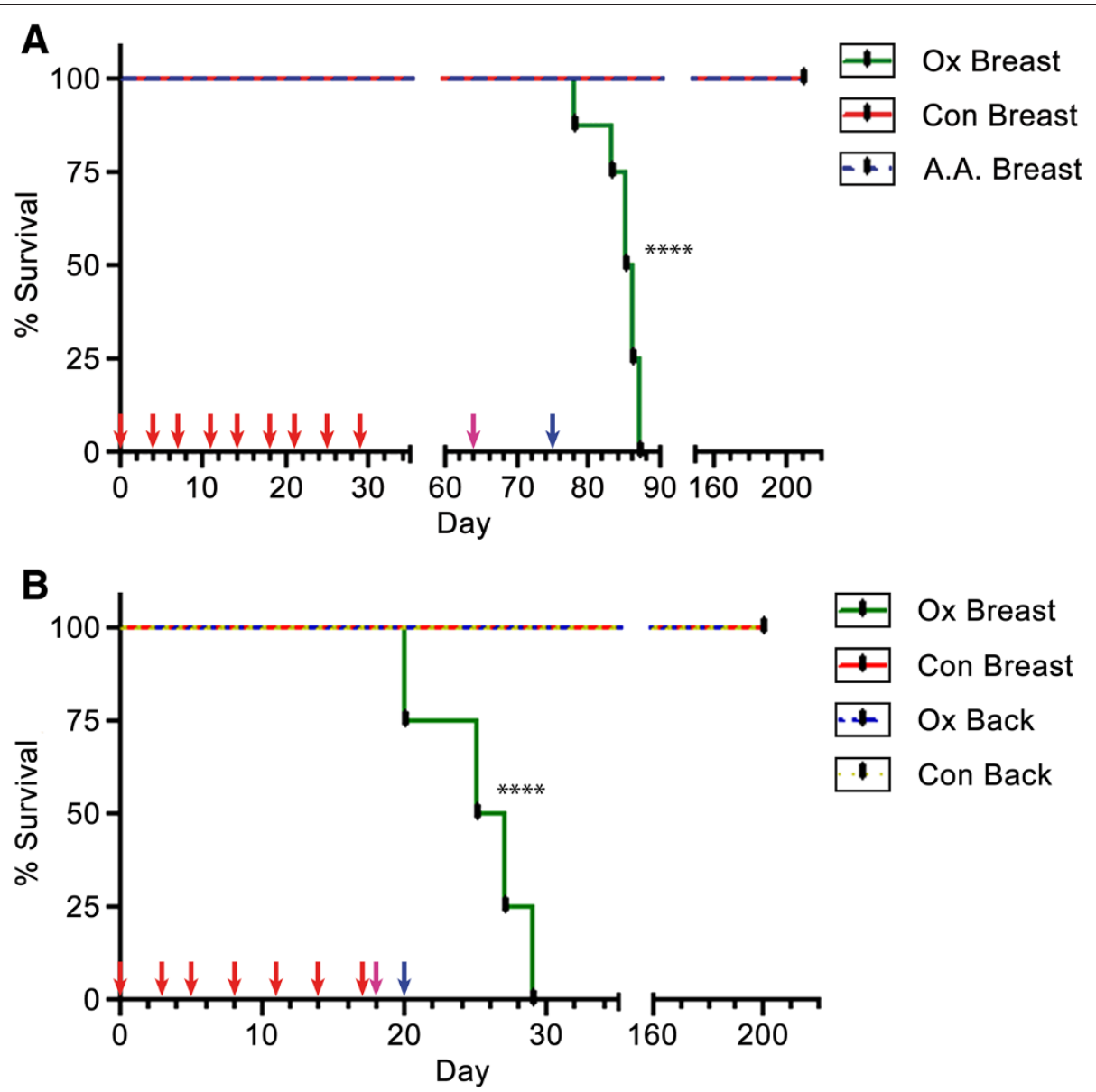

Fig. 5 Oxalate induces tumor formation and short-term survival in mice. a Mice were injected every 3 or 4 days into mammary fat pad to reach 9 doses (one dose every 3.2 days on average). The experimental group (Ox Breast) received $50 \mu \mathrm{L}$ of a solution with microcrystals of calcium oxalate (oxalic acid $810 \mu \mathrm{M}$ in a carrier solution containing $\mathrm{CaCl}_{2} 1.8 \mathrm{mM}$ ). The two control groups received $50 \mu \mathrm{L}$ of either carrier solution containing $\mathrm{CaCl}_{2} 1.8 \mathrm{mM}$ (Con Breast) or a solution of carrier solution plus acetic acid $810 \mu \mathrm{M}$ (A.A. Breast). Each group consisted of 8 mice. b Mice were injected every 2 or 3 days to reach 7 doses (one dose every 2.6 days on average). Experimental groups received injections with $50 \mu \mathrm{L}$ of saline solution containing potassium oxalate $810 \mu \mathrm{M}$ either at the mammary fat pad (Ox Breast) or in the Back (Ox Back). Control groups were injected at the same places as the experimental ones with saline solution only into mammary fat pad (Con Breast) or into the back (Con Back). Each group consisted of 5 mice. Red arrows: times of injection. Pink arrows: time of the first tumor appearance in Ox Breast group. Blue arrows: time at which all mice of Ox breast group have at least one tumor. Statistical significance between survival curves was analyzed by LogRank (Mantel-Cox) test. ****P value $<0.0001$

only of $2.5 \mu \mathrm{M}$. Although this concentration is low, we previously showed that even $1 \mu \mathrm{M}$ of oxalate is capable of inducing breast cells to proliferate in vitro after 3 weeks of treatment (Fig. 2b). Consequently, a new series of experiments were conducted in which six mice of the experimental groups were injected with potassium oxalate $810 \mu \mathrm{M}$ in saline solution to avoid the formation of oxalate microcrystals in the solution injected. Additionally, saline solution was used as control and both, potassium oxalate solution and carrier solution were injected either in the fat pad or in the back of the animal to evaluate tissue-specificity of oxalate to generate tumors $(n=6$, each animal group). Mice received seven doses, one injection every 2 or 3 days in a period of 18 days (a dose every 2.6 days on average). Surprisingly, the group of mice injected with oxalate solution at the mammary fat pad area was the only group that generated tumors. On day 18 , a mouse of this group ( 1 of 5 mice) had already generated one tumor at the mammary fat pad and on day 20, all mice had at least one tumor and three of them had generated several tumors in the chest region. On the other hand, none of the mice of the others three groups developed tumors, that is, neither the mice injected with potassium oxalate or carrier solution into the back nor the mice injected with carrier solution into the mammary fat pad. These groups were kept under observation up to six months after the last injection, time at which tumor formation was not observed. After that, all mice were euthanized and the absence of tumor formation in all organs was confirmed in the control groups by histological 


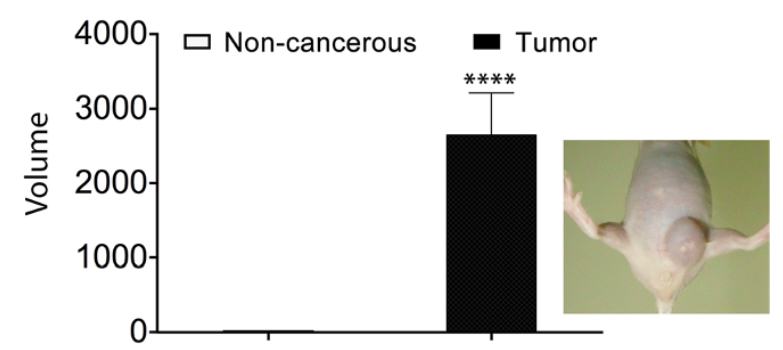

Fig. 6 Oxalate-treated mice generated tumors. Mice were injected every 2 or 3 days with $50 \mu \mathrm{L}$ of saline solution containing oxalate $810 \mu \mathrm{M}$ at into mammary fat pad. Control groups were injected at the same places than the experimental ones with saline solution. Tumor volume $(\mathrm{v})$ of the mice treated were measured and calculated in accordance with the method of Attia and Weiss [35] To the right it has been included a photograph of a typical tumor induced by oxalate in mice. Each experimental group consisted of 9 animals per group. Results were analyzed for statistical significance using Student's two tailed $t$-test. ${ }^{* * *} p$ value $<0.0001$

analysis (Fig. 5b). Statistical analysis of the survival curves of the animals performed using the LogRank (MantelCox) test showed that the survival times of the animals treated with oxalate in the mammary area was significantly shorter than that of the animals that received oxalate in the animal's back (no tumor) or those receiving carrier solution alone (Fig. 5a and b).

This is the first demonstration the oxalate produces breast cancer tumors in vivo and also promotes shortterm survival. Moreover oxalate tissue specificity was observed indicating that there is something in the breast cells necessary for oxalate to induce tumor formation since no tumors were formed when oxalate was injected in the mice back, nor was fibroblast cell proliferation observed when oxalate was added to the culture medium (Fig. 2a and Additional file 1: Figure S1).

\section{Analysis of mice's breast tumors generated by oxalate} The concentration of oxalate was quantified by CEC in seven samples of mice's breast tumor tissues, which were developed after oxalate treatments in vivo, and in seven samples of non-cancerous breast tissues of control mice. As expected, breast tumor tissues had higher concentrations of oxalate than non-cancerous breast tissues (Fig. 7). Additionally, sections of the mammary fat pad tumors were stained using H\&E. Two independent Pathologists reported that the neoplastic growth that was found corresponds to a highly malignant lineage, undifferentiated, with characteristics of Fibrosarcoma of the breast. In these tumors, cells generally adopt a pattern arranged in fascicles of spindle cells, integrated sharp ends and large ovoid nuclei currents. In other areas of the tumor, cells are polyhedral with acidophilic cytoplasm, a highly pleomorphic angular nuclei with macronucleoli and numerous nucleoli. Upon examination of samples at under a microscope using

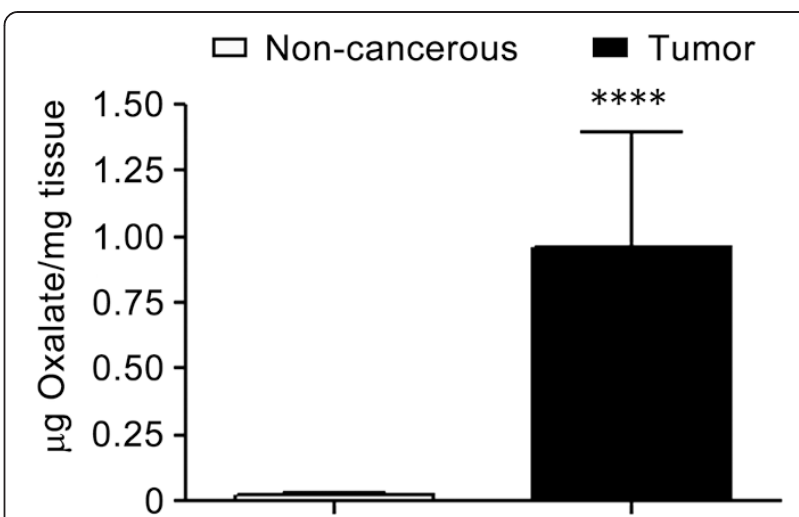

Fig. 7 Mice breast tumor tissues contain higher concentrations of total Oxalate than non-cancerous breast tissues. Seven samples of mice breast tumor tissues (Tumor samples) and seven samples of non-cancerous breast tissues (Control samples) were homogenized in $2.75 \mathrm{M} \mathrm{HCl}$. The supernatant fractions were analyzed by Capillary Electrochromatography to establish the total concentration of Oxalate present in each sample. Results expressed as $\mu \mathrm{g} / \mathrm{mg}$ tissue were analyzed for statistical significance by Student's two tailed $t$-test. All graph were performed using GraphPad Prism version 6.0e for Mac OS X (GraphPad Software, La Jolla California USA) ${ }^{* * *} P$ value $<0.001$

a 40X magnifier, high mitotic activity was found; over five figures per $40 \mathrm{X}$ field, and atypical mitosis were also observed. Interestingly, in the breast ducts, multinuclear and abnormal epithelial breast cells were found. Immunohistochemistry of the tumors showed a marked positivity for Vimentin and low positivity to S100 protein, cytokeratin E1 to E3 and MSA (mammary serum antigen).

In the breast tissues of all control groups (DoubleBlind histological sections) of both experiments in vivo (mice treated with carrying solution or acetic acid at the mammary fat pad and those mice treated with oxalate or carrying solution at the back region) no tumor cells were found by $\mathrm{H} \& \mathrm{E}$ (Fig. 8).

On the other hand, sample sections from mice breast tumors (generated after treatment with oxalate) and noncancerous breast tissues of control mice were examined by immunohistochemistry. In breast sections was seen that tumor tissues express significantly higher amounts of c-Fos than non-cancerous breast tissues (Fig. 9a). To further confirm this, these samples were analyzed by q-RTPCR for c-fos expression. The same result was observed, tumor samples express higher levels of c-Fos m-RNA than breast control samples (Fig. 9b).

\section{Discussion}

In the present study, the capacity of free oxalate to induce proliferation of MCF-7 and MDA-MB231 breast cancer cell lines has been demonstrated for the first time. Furthermore, it has also been demonstrated that oxalate slightly induces proliferation in a normal breast cell line such as MCF10A. In the same line, all the Balb/ 


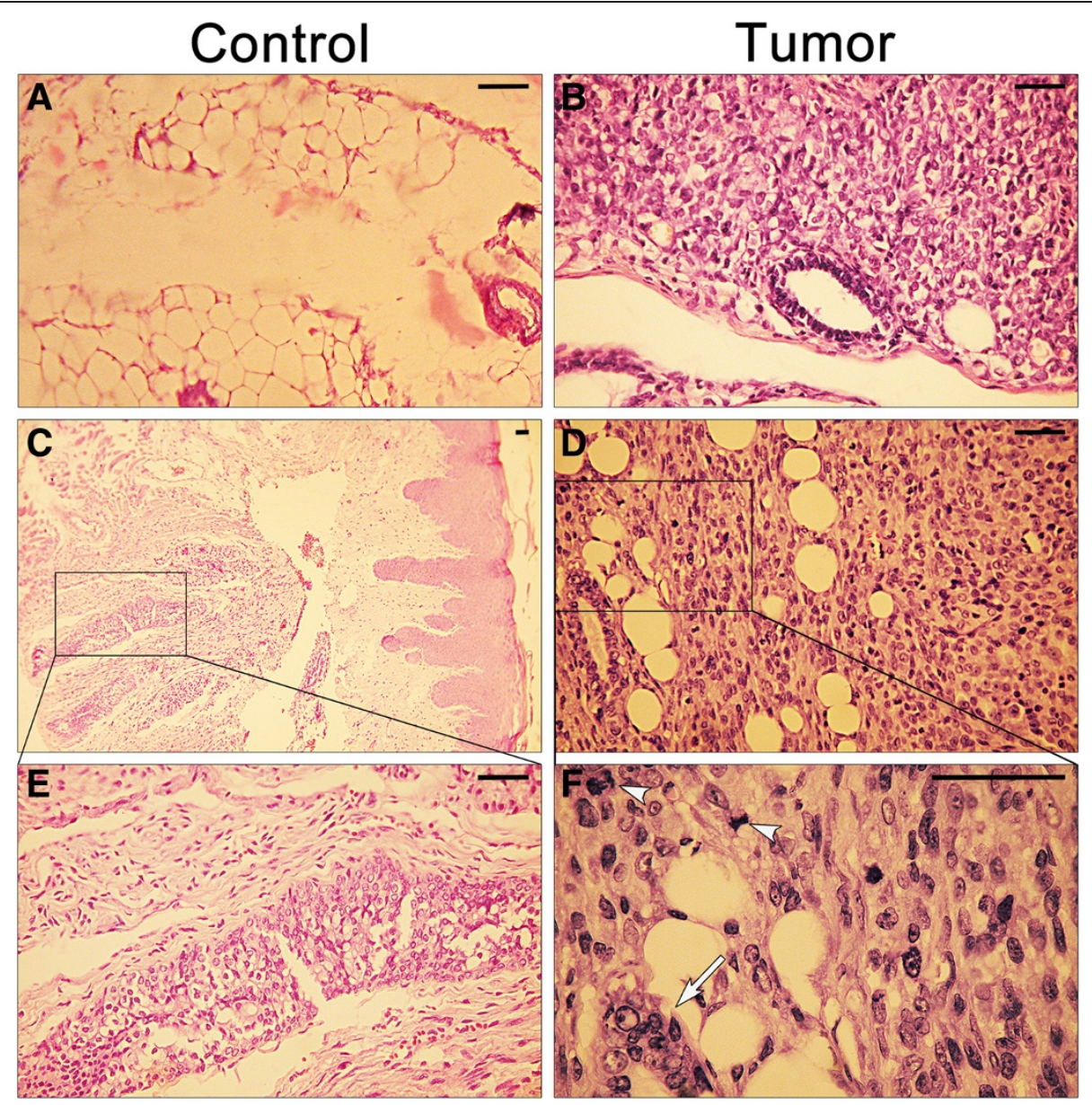

Fig. 8 Oxalate-treated mice generated undifferentiated and highly aggressive tumors. H\&E staining of two representative sections of both non-cancerous breast tissue ( $\mathbf{a}$ and $\mathbf{b}$ ) and breast mice tumor tissues ( $\mathbf{d}$ and $\mathbf{e}$ ), generated after treatment with oxalate, are shown. Panels $\mathbf{c}$ and $\mathbf{f}$ are enlargements of the areas delimited in panels $\mathbf{b}$ and $\mathbf{e}$ respectively. Panel $\mathbf{f}$ mitotic figures (arrowheads) and abnormal epithelial breast duct cells (arrow) are marked. A total of 13 tumors and of 13 non-tumor tissues were examined. In all cases, animals treated with oxalate generated malignant, undifferentiated tumors with the characteristics of fibrosarcoma of the breast. Scale bar $50 \mu \mathrm{m}$

c nude mice that receive injections containing oxalate at the mammary fat pad region generate breast tumors showing a marked carcinogenic effect of oxalate. Different periods of time were required for each treatment to promote breast cancer and such times were directly proportional to the effective concentration of free oxalate in the solution injected. A higher concentration of free oxalate produces breast tumors more quickly. This correlation between the concentration of free oxalate and the velocity to generate breast tumors strongly supports the role of oxalate as a carcinogen chemical agent for breast tissue. Furthermore, clear differences were observed between the survival time and also between the size of tumors originated in the groups of animals that were treated with oxalate in the mammary area versus control animals treated with oxalate in the back or receiving carrier solution alone. The neoplastic growth that was found corresponds to a highly malignant, undifferentiated lineage with characteristics of a fibrosarcoma of the breast. Interestingly, in breast ducts it was observed multinuclear and abnormal epithelial breast cells. Immunohistochemistry of the tumors showed a marked positivity for Vimentin and low positivity to S100 protein, cytokeratin E1 to E3 and MSA that is compatible with the tumor described. Our working hypothesis is that oxalate is inducing an epithelial breast cell transformation such as the epithelialmesenchymal transition. The capacity of oxalate to produce breast cancer is also supported by in vitro experiments in which different concentrations of oxalate, in a range between 20 to $50 \mu \mathrm{M}$, induce proliferation of human breast cell lines. Furthermore, concentrations of oxalate lower than $20 \mu \mathrm{M}$ cause a similar effect on proliferation after a longer exposure time. The fact that oxalate can induce human breast cancer cells to proliferate in vitro is not minor. It is interesting to try to extrapolate the carcinogenic effect of oxalate in mice to a possible effect in human. It is 

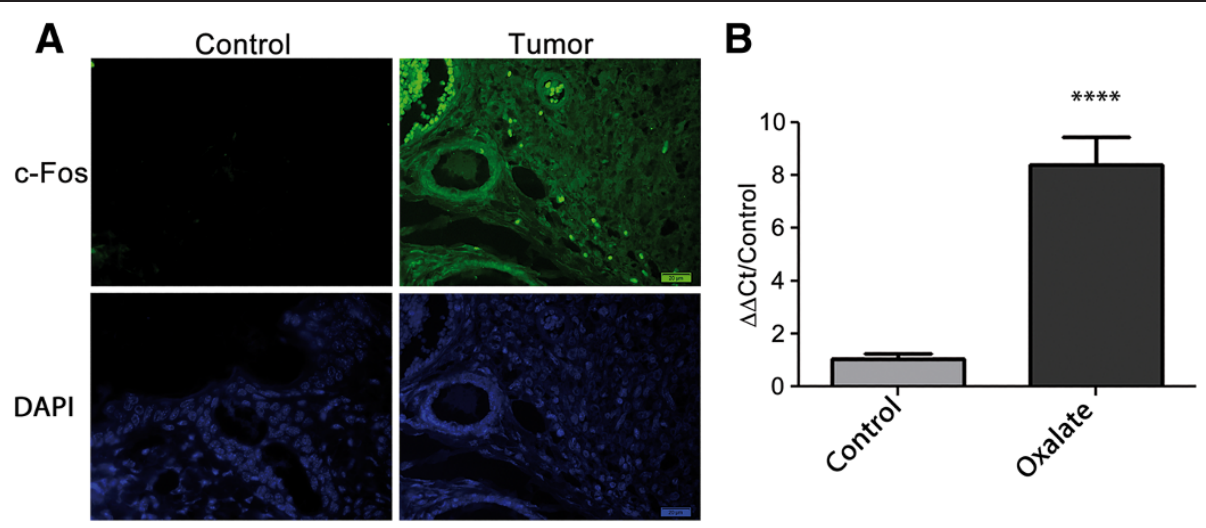

Fig. 9 Mice breast tumor tissues express higher amounts of c-Fos than non-cancerous breast tissues. a Sections of both breast tumor tissues ( $n=6$ ) and non-cancerous breast tissues $(n=6)$ were adhered to uncharged slides. c-Fos expression was seen by immunohistochemical staining (green) and nuclei were visualized with DAPI (blue). Shown is a representative figure of all slides analyzed. A minimum if 3 sections were examined per tissue sample. $\mathbf{b}$ c-fos expression was measured in breast tumor tissues $(n=5)$ and non-cancerous breast tissues $(n=5)$ by qRT-PCR and normalized against the housekeeping gene Tbp using the Sequence Detection Software v1.4. A difference in c-fos expression was statistically analyzed by Student's two tailed $t$-test. ${ }^{* * *} P$ value $<0.001$

important to highlight that we have obtained similar results to those of MP Morgan et al. 2012 [11], in which microcrystals of calcium oxalate did not induce proliferation of the breast cancer cell lines MCF-7 and MDA-MB23. We have seen that only oxalate as the free ion, has a carcinogenic potential, but not calcium oxalate crystals. Moreover, oxalate induced tumor formation only when it was injected into the breast tissue of mice but not when injected into the back of the animals, indicating that it does not induce cancer formation in any type of tissue. Actually, we do not know if oxalate can induce tumor formation in tissues other than breast tissue. In this respect, the ability of oxalate to induce cells to proliferate was only seen with breast cell lines. That is, neither human kidney epithelial cells (HEK293) nor mouse fibroblast cells (NIH/3 T3) proliferate when treated with oxalate. These are strong signals that lead us to hypothesize that the carcinogenic potential of oxalate is specific for breast tissue, although more experiments with a broader range of tissues are needed to confirm this. It is evident that the immune system plays a very important role in tumor formation. Balb/c nude mice were more sensitive to the treatment with oxalate than mice with a wild type immune system (BALB/c mice). When BALB/c mice were treated with oxalate using the same experimental conditions, no tumor development was observed at the same period of time. Furthermore, we maintained the animals under observation for more than six-months and no tumor formation was observed either. We only observed a little swelling of the mammary fat pad area in some animals a week after the last injection with oxalate solution but this swelling disappeared within 24 to $48 \mathrm{~h}$ (data not shown). We believe that oxalate could have initiated tumor formation although they never generated a palpable, fully developed tumor probably because the immune system response was sufficient to destroy these cells.

\section{Conclusions}

In the present study the capacity of free oxalate to induce breast cell lines proliferation in vitro has been demonstrated for the first time. MCF-7, MDA-MB231 and MCF-10A cells treated with oxalate at concentrations of 20 and $50 \mu \mathrm{M}$ clearly showed higher rates of proliferation than their respective controls. Furthermore, the carcinogenic capacity of oxalate was observed only when injected into the breast area of mice. In in vivo experiments, oxalate induced tumor formation when it was injected periodically into the breast tissue of Balb/c nude mice with a $100 \%$ of penetrance. It is important to note that treatment of mice with potassium oxalate induced tumor formation more rapidly than the treatment with micro crystals of calcium oxalate although the final concentration of oxalate was the same in both cases. Probably these differences are due to the fact that calcium oxalate is poorly soluble and the concentration of free oxalate, as ion, in the equilibrium is very low. On the other hand, potassium oxalate is highly soluble and all oxalate exists in its ionic form in solution at the concentrations used. Therefore, we conclude that free oxalate, as a ion, is the chemical specie that has the carcinogenic effect on breast tissue. The tumors generated were highly malignant, undifferentiated and with the characteristics of fibrosarcomas of the breast. Moreover, we have demonstrated the ability of free oxalate to induce the expression of an IEG as c-Fos in MCF-7 breast cancer cells in vitro. Previously, it had been reported the ability of oxalates to produce changes in the expression level of many genes in a human 
kidney cell line [21] but this is the first time that an effect of oxalates was demonstrated in a human breast cell line. The mechanism by which oxalate exerts its action on breast cells is still largely unknown and further research is needed to elucidate it. However, it is expected that a significant reduction in the incidence of breast cancer tumors could be reached if it were possible to control the oxalate production or its carcinogenic activity.

\section{Additional files}

Additional file 1: Figure S1. Oxalate induces proliferation of breast cancer cells but not of HEK-293 and NIH-3 T3 cells. Proliferation was measured in MCF-7, MDA-MB231, HEK-293 and NIH-3 T3 cells after 3 days of treatment by counting cells in a Neubauer Chamber. Cells were cultured in DMEM medium plus an additional specific reagent or not, according to each condition. Con: Control, none additional reagent. FBS: fetal bovine serum. Ox: oxalic acid. A.A.: acetic acid. Bars represent the standard error of the mean of three independent experiments performed in triplicate. Statistical significance determined by Two-way ANOVA with Holm-Sidak's multiple comparison test $(a=0.05)$ was performed in experiments graphed in Additional file 1: Figure S1. ${ }^{* * *} P<0.0001$. (TIFF $2135 \mathrm{~kb}$ )

Additional file 2: Figure S2. Oxalate does not induce c-Fos expression in $\mathrm{NIH}-3 \mathrm{~T} 3$ cells. Cells were plated in six wells and growing up until $80 \%$ of confluence. Then cells were starved to achieve quiescence (see Material \& Methods). After that, cells were stimulated during $1.5 \mathrm{~h}$ with a specific reagent according to each condition. $\mathrm{NIH}-3 \mathrm{~T} 3$ cells were lysed and the supernatant fractions were separated in $12 \%$ SDS-PAGE gel and immunoblotted using anti-c-Fos antibody. a-Tubulin was used as loading control. Con: Control, none additional reagent. FBS: fetal bovine serum. Ox: oxalic acid. A.A.: acetic acid. (TIFF $130 \mathrm{~kb}$ )

Additional file 3: Figure S3. Oxalate does not induce c-Jun expression in MCF-7 cells. Cells were plated in six wells and growing up until $80 \%$ of confluence. Then cells were starved to achieve quiescence (see $M \& M$ ). After that, cells were stimulated during $1.5 \mathrm{~h}$ with a specific reagent according to each condition. MCF-7 cells were lysed and the supernatant fractions were separated in $12 \%$ SDS-PAGE gel and immunoblotted using anti-c-Jun antibody. a-Tubulin was used as loading control. Con: Control, none additional reagent. FBS: fetal bovine serum. Ox: oxalic acid. A.A.: acetic acid. (TIFF $132 \mathrm{~kb}$ )

\begin{abstract}
Abbreviations
$\mathrm{CaCl}_{2}$ : Calcium chloride; CaOx: Calcium oxalate; CaP: Hydroxyapatite; qRTPCR: Quantitative- real time -PCR; CEC: Capillary electrochromatography; DCIS: Ductal carcinoma in situ; EGF: Epidermal Growth Factor; FBS: Fetal bovine serum; $\mathrm{HCl}$ : Hydrochloric Acid; H\&E: Hematoxylin and eosin stain; IEG: Immediate early gene; mA: Milliampere; mAb: Monoclonal antibody; MAPK: Mitogen-activated protein kinase; MF: Microsomal fraction; mM: Millimolar; $\mu$ M: Micromolar; SDS: Sodium dodecyl sulfate; SF: Supernatant fraction; TH: Total homogenate.
\end{abstract}

\section{Competing interests}

The authors declare that they have no competing interests.

\section{Authors' contributions}

A.M.C. planned and performed experiments, processed data, discussed the results and participated in the preparation of the paper. H.C. performed experiments. A.T. discussed the results. H.F discussed the results. B.L.C. discussed the results and participated in the preparation of the paper. O.A.P. planned experiments, discussed the results and participated in the preparation of the paper. G.A.G. planned and performed experiments, processed data, discussed the results and participated in the preparation of the paper. All authors have read and approved the manuscript.

\section{Acknowledgements}

We acknowledge the support of by the Secretaria de Ciencia y Técnica, Universidad Nacional de Córdoba (grant number 164 and 162/12), The Agencia Nacional de Promoción Científica y Tecnológica - The Fondo para la Investigación Científica y Tecnológica (grant number PICT 2012-2797) and APRADOC. G.A.G. and B.L.C. are investigators of CONICET. A.M.C. is a fellow of CONICET (Consejo Nacional de Investigaciones Científicas y Tecnológicas), Ministerio de Ciencia y Tecnología, Argentina. We thank Dr. C. Giraudo and D. Assum (Fundación para el Progreso de la Medicina, FPM, Córdoba, Córdoba, Argentina), for kindly providing us with the technical assistance with CEC and Susana Deza for providing us with T.C. assistance (CIQUIBIC, CONICET, Universidad Nacional de Córdoba, Córdoba, Argentina. I also thanks to all members of Caputto's lab for excellent and helpful discussions.

\section{Author details}

'Departamento de Química Biológica, Facultad de Ciencias Químicas, Universidad Nacional de Córdoba- CIQUIBIC, CONICET, Córdoba, Argentina. ${ }^{2}$ Primera Cátedra de Ginecología, Hospital Nacional de Clínicas, Universidad Nacional de Córdoba, Córdoba, Argentina. ${ }^{3}$ Cátedra de Patología, Hospital Nacional de Clínicas, Universidad Nacional de Córdoba, Córdoba, Argentina.

Received: 12 November 2014 Accepted: 9 October 2015

Published online: 22 October 2015

\section{References}

1. DeSantis C, Lin C, Mariotto A, Siegel R, Stein K, Kramer J, et al. Cancer treatment and survivorship statistics, 2014. CA Cancer J Clin. 2014;64(4):252-71.

2. Siegel R, Ma J, Zou Z, Jemal A. Global cancer statistics. CA Cancer J Clin. 2014;61(2):69-90

3. Hofvind S, Iversen BF, Eriksen L, Styr BM, Kjellevold K, Kurz KD. Mammographic morphology and distribution of calcifications in ductal carcinoma in situ diagnosed in organized screening. Acta Radiol. 2011;52(5):481-7.

4. Holme TC, Reis MM, Thompson A, Robertson A, Parham D, Hickman P, et al. Is mammographic microcalcification of biological significance? Eur J Surg Oncol. 1993;19(3):250-3.

5. Seo BK, Pisano ED, Kuzimak CM, Koomen M, Pavic D, Lee Y, et al. Correlation of HER-2/neu overexpression with mammography and age distribution in primary breast carcinomas. Acad Radiol. 2006;13(10):1211-8.

6. Wang $X$, Chao L, Chen L, Tian B, Ma G, Zang Y, et al. Correlation of mammographic calcifications with Her-2/neu overexpression in primary breast carcinomas. J Digit Imaging. 2008;21(2):170-6.

7. Frappart L, Boudeulle M, Boumendil J, Lin HC, Martinon I, Palayer C, et al. Structure and composition of microcalcifications in benign and malignant lesions of the breast: study by light microscopy, transmission and scanning electron microscopy, microprobe analysis, and X-ray diffraction. Hum Pathol. 1984;15(9):880-9.

8. Singh N, Theaker J. Calcium Oxalate Crystals (Weddellite) within the secretions of ductal carcinoma in situ : a rare phenomenon. J Clin Pathol. 1999;52(2):145-6.

9. Gonzalez JE, Caldwell RG, Valaitis J. Calcium oxalate crystals in the breast Pathology and significance. Am J Surg Pathol. 1991;15(6):586-91.

10. Erdener Özer MD, Tülay Canda MD, Pınar Balcı MD, Özcan Gökçe MD. Calcium Oxalate Crystals in Benign Cyst Fluid from the Breast. Acta Cytol. 2008:99:0281-7.

11. Cox RF, Hernandez-Santana A, Ramdass S, McMahon G, Harmey JH, Morgan MP. Microcalcifications in breast cancer: novel insights into the molecular mechanism and functional consequence of mammary mineralisation. $\mathrm{Br}$ J Cancer. 2012;106(3):525-37.

12. Scimeca M, Giannini E, Antonacci C, Pistolese C, Spagnoli L, Bonanno L. Microcalcifications in breast cancer: an active phenomenon mediated by epithelial cells with mesenchymal characteristics. BMC Cancer. 2014;14:286.

13. ÇalişKan M. The Metabolism of Oxalic Acid. Turk J Zool. 1998;24(2000):103-6.

14. Çaliş̧Kan M, Subasi IE, Atak I, Erdem H, Sisik A, Ucankale H, et al. Hydatid cyst of the breast. Breast J. 2011;17(2):203-4.

15. Panjwani $P$, Tirumalae $R$, Emmanuel A. Calcium oxalate crystals-an unexpected finding in a breast aspirate. Diagn Cytopathol. 2011;39(5):349-51.

16. Robertson DS. The function of oxalic acid in the human metabolism. Clin Chem Lab Med. 2011;49(9):1405-12.

17. Lange JN, Wood KD, Knight J, Assimos DG, Holmes RP. Glyoxal formation and its role in endogenous oxalate synthesis. Adv Urol. 2012;2012:819202. 
18. Baker PR, Cramer SD, Martha K, Assimos DG, Holmes RP. Glycolate and glyoxylate metabolism in HepG2 cells. Am J Physiol Cell Physiol. 2004;287:C1359-65.

19. Koul S, Khandrika L, Pshak TJ, Iguchi N, Pal M, Steffan JJ, et al. Oxalate upregulates expression of IL-2R and activates IL-2R signaling in HK-2 cells, a line of human renal epithelial cells. Am J Physiol Renal Physiol. 2014;306:1039-46.

20. Janet R, Durham M, Fechner RE. The histologic spectrum of apocrine lesions of the breast. Pathol Patterns Rev. 2000;113 Suppl 1:3-18.

21. Koul S, Khandrika L, Meacham RB, Koul HK. Genome wide analysis of differentially expressed genes in HK-2 cells, a Line of human kidney epithelial cells in response to oxalate. PLoS One. 2012;7(9):e43886.

22. Koul S, Chaturved LS, Sekhon A, Bhandari A, Menon M, Koul HK. Effects of oxalate on the re-initiation of DNA synthesis in LLC-PK1 cells do not involve p42/44 MAP kinase activation. Kidney Int. 2002;61(2):525-33.

23. Maroni PD, Koul S, Meacham RB, Chandhoke PS, Koul HK. Effects of oxalate on IMCD cells: a line of mouse inner medullary collecting duct cells. Ann N Y Acad Sci. 2004;1030:144-9.

24. Koul S, Huang M, Bhat S, Maroni P, Meacham RB, Koul HK. Oxalate exposure provokes HSP 70 response in LLC-PK1 cells, a line of renal epithelial cells: protective role of HSP 70 against oxalate toxicity. Urol Res. 2008;36(1):1-10.

25. Huang MY, Chaturvedi LS, Koul S, Koul HK. Oxalate stimulates IL-6 production in HK-2 cells, a line of human renal proximal tubular epithelial cells. Kidney Int 2005:68:497-503.

26. Peters MS, Lehman JS, Comfere NI. Dermatopathology of the female breast. Am J Dermatopathol. 2013;35(3):289-304. quiz 305-287.

27. Gil GA, Silvestre DC, Tomasini N, Bussolino DF, Caputto BL. Controlling cytoplasmic c-Fos controls tumor growth in the peripheral and central nervous system. Neurochem Res. 2012;37(6):1364-71.

28. Bland JM, Altman DG. The logrank test. BMJ. 2004;328:1073.

29. Bussolino DF, Guido ME, Gil GA, Borioli GA, Renner ML, Grabois VR, et al. c-Fos associates with the endoplasmic reticulum and activates phospholipid metabolism. FASEB J. 2001;15(3):556-8.

30. Caputto BL, Cardozo Gizzi AM, Gil GA. c-Fos: an AP-1 transcription factor with an additional cytoplasmic, non-genomic lipid synthesis activation capacity. Biochim Biophys Acta. 2014;1841(9):1241-6.

31. Gil GA, Bussolino DF, Portal MM, Alfonso Pecchio A, Renner ML, Borioli GA, et al. c-Fos activated phospholipid synthesis is required for neurite elongation in differentiating PC12 cells. Mol Biol Cell. 2004;15(4):1881-94.

32. Chaturvedi LS, Koul S, Sekhon A, Bhandari A, Menon M, Koul HK. Oxalate selectively activates p38 mitogen-activated protein kinase and c-Jun Nterminal kinase signal transduction pathways in renal epithelial cells. J Biol Chem. 2002:277(15):13321-30.

33. Liska V, Holubec Jr L, Treska V, Vrzalova J, Skalicky T, Sutnar A, et al. Evaluation of tumour markers as differential diagnostic tool in patients with suspicion of liver metastases from breast cancer. Anticancer Res. 2011;31(4):1447-51.

34. Motrich RD, Castro GM, Caputto BL. Old players with a newly defined function: Fra-1 and c-Fos support growth of human malignant breast tumors by activating membrane biogenesis at the cytoplasm. PLoS One. 2013:8(1):e53211.

35. Attia MA, Weiss DW. Immunology of spontaneous mammary carcinomas in mice. $V$. Acquired tumor resistance and enhancement in strain A mice infected with mammary tumor virus. Cancer Res. 1996;8:1787-800.

\section{Submit your next manuscript to BioMed Central and take full advantage of:}

- Convenient online submission

- Thorough peer review

- No space constraints or color figure charges

- Immediate publication on acceptance

- Inclusion in PubMed, CAS, Scopus and Google Scholar

- Research which is freely available for redistribution

Submit your manuscript at www.biomedcentral.com/submit 